University of Nebraska - Lincoln

DigitalCommons@University of Nebraska - Lincoln

$11-19-2007$

\title{
Livestock production system management responses to thermal challenges
}

\author{
J. A. Nienabar
}

USDA-ARS

G. L. Hahn

USDA-ARS, hahn@email.marc.usda.gov

Follow this and additional works at: https://digitalcommons.unl.edu/usdaarsfacpub

Part of the Agricultural Science Commons

Nienabar, J. A. and Hahn, G. L., "Livestock production system management responses to thermal challenges" (2007). Publications from USDA-ARS / UNL Faculty. 217.

https://digitalcommons.unl.edu/usdaarsfacpub/217

This Article is brought to you for free and open access by the U.S. Department of Agriculture: Agricultural Research Service, Lincoln, Nebraska at DigitalCommons@University of Nebraska - Lincoln. It has been accepted for inclusion in Publications from USDA-ARS / UNL Faculty by an authorized administrator of DigitalCommons@University of Nebraska - Lincoln. 


\title{
Livestock production system management responses to thermal challenges
}

\author{
J.A. Nienaber • G.L. Hahn
}

Received: 30 June 2006 /Revised: 5 October 2006 / Accepted: 15 October 2006 / Published online: 25 May 2007

\begin{abstract}
The adaptive capabilities of animals and livestock production systems have been emphasized in this report. Biometeorology has a key role in rational management to meet the challenges of thermal environments. While the focus is primarily on cattle in warm or hot climates, the importance of dynamic animal responses to environmental challenges applies to all species and climates. Methods used to mitigate environmental challenges focus on heat loss/heat production balance. Under cold stress, reduction of heat loss is the key. Under heat stress, reduction of heat load or increasing heat loss are the primary management tools, although heat-tolerant animals are also available. In general, livestock with health problems and the most productive animals (e.g., highest growth rate or milk production) are at greatest risk of heat stress, thereby requiring the most attention. Risk management, by considering perceived thermal challenges, then assessing the potential consequences and acting accordingly, will reduce the impact of such challenges. Appropriate actions include: shade, sprinkling, air movement, or active cooling. Summarizing, the most important element of proactive environmental management to reduce risk is preparation: be informed, develop a strategic plan, observe and recognize animals in distress, and take appropriate tactical action.
\end{abstract}

Keywords Heat stress · Proactive management .

Stressor mitigation $\cdot$ Risk assessment $\cdot$ Animal response

J. Nienaber $(\bowtie) \cdot$ G. Hahn

USDA-ARS U.S. Meat Animal Research Center,

Clay Center, NE, USA

e-mail: nienaber@email.marc.usda.gov

\section{Introduction}

The care and feeding of livestock around the world is impacted by climate and weather factors. Sustainable production of livestock requires advanced planning of production management systems, with an understanding of negative animal responses that signal environmental stress and the ability to implement appropriate practices to ameliorate stress effects. Thermal challenges range from cold to hot and are species- and life-cycle-dependent. Livestock managers have always had to address such challenges for the benefit of their animals from the standpoints of managerial acceptability, technological feasibility, and economic return. Modern production systems can be designed to manage thermal challenges in specific locations; however, sustainability ultimately determines which options are most appropriate. With production systems located in many climate zones currently experiencing greater variation in climate extremes, an essential question becomes "How do we adapt our livestock production systems to meet the thermal challenges of current and future climates?" Biometeorology plays a key role in rational environmental management of livestock by providing the bridge between biological responses of livestock and production agriculture. Livestock production systems that provide management and shelter options to mitigate thermal environmental challenges can reduce the risk of adverse consequences.

The objectives of this report are to: define the thermal challenges that create negative animal responses, to characterize those animal responses so that they can be recognized and ameliorated, and finally to describe effective management practices for that stress management. 


\section{Thermal challenges}

In general, cold climates are manageable to obtain suitable microclimates through protective shelters with or without thermal modification. Design criteria and related information are available in various publications for construction and maintenance of appropriate livestock environments to provide for animal well being and to ensure performance [e.g., ASAE Standards (ASAE 2003), ASHRAE and Midwest Plan Service Handbooks (ASHRAE 2005; MWPS 1987) and CIGR Handbooks (Flaba et al. 2002)]. Swine and poultry production systems in thermally challenging areas often incorporate protective measures against thermal extremes. However, problems persist for livestock production under severe climate conditions, especially during heat stress conditions, whether animals are in shelters or open lots. While severe cold climate conditions (e.g., blizzards, extreme windchill) in early fall and winter can be life threatening, high temperature weather patterns often present short-term stressful conditions that find the livestock producer unprepared. These short-term, high-intensity hot weather patterns are referred to as 'heat waves' (Hahn et al. 1999).

For cattle, heat waves have caused many documented localized but economically devastating events with many animal deaths: 700 dairy cows in southern California (Oliver et al. 1979); more than 3,000 feedlot cattle in Queensland, Australia (Blackshaw and Blackshaw 1991); more than 500 feedlot cattle in eastern Nebraska (Hahn 1995b); more than 4,000 feedlot cattle in Nebraska and Iowa (Hahn and Mader 1997); more than 5,000 feedlot cattle in eastern Nebraska (Hungerford et al. 2000), 1,200 cattle in Australia in 2000 (John Gaughan, personal communication), and over 25,000 cattle and 700,000 poultry in California in 2006 (USAgNet 2006). Each of these events was relatively short-term and generated investigations into characteristic weather patterns to describe the events. The combined impact of temperature and humidity, expressed as the temperature-humidity index (THI), is a derived statistic (adapted from Thom 1959):

$\mathrm{THI}=0.8 \mathrm{t}_{\mathrm{db}}+\mathrm{RH}\left(\mathrm{t}_{\mathrm{db}}-14.4\right)+46.4$.

Where $t_{\mathrm{db}}=$ dry-bulb air temperature $\left({ }^{\circ} \mathrm{C}\right)$ and $\mathrm{RH}=$ relative humidity in decimal form.

In an early effort to provide guidelines for safe transportation of animals, the Livestock Weather Safety Index (LWSI; LCI 1970) was developed to classify the combined intensity of temperature and humidity into four categories of THI values: Normal, less than or equal to 74; Alert, 7578; Danger, 79-83; and Emergency, greater than or equal to 84. Experience over time suggested that the THI-based LWSI was a valuable tool for producers, even though it lacked recognition of the effects of thermal radiation and wind speed. Warnings, with respect to these categories, were issued by the United States Weather Bureau to alert producers to potential heat stress conditions. However, that service was discontinued because of budget constraints and availability of commercial services.

Although the THI was valuable, it lacked other important factors to adequately classify heat waves. A climatological analysis was made of heat wave events occurring mid-June through mid-September from 1949 to 1991 at a south central Nebraska (US) location (Hahn et al. 1999). Based on the criterion that a heat wave was of at least 3 days duration with THI greater than or equal to 70 for all hours, there were 42 heat waves identified over the 43 -year period, ranging from 0 to 4 per year. Table 1 summarizes that assessment, incorporating persistence and night-time cooling into categories of intensity affecting feedlot cattle.

The most devastating heat waves generally occurred in the early summer period before animals were acclimatized to high temperatures. Consequences were mild for many of the heat waves that occurred in late summer, probably reflecting livestock acclimatization. The concept of THI-hr was intro-

Table 1 Heat wave categories for Bos taurus feedlot cattle exposed to single heat wave events (Hahn et al. 1999)

Descriptive characteristics ${ }^{\mathrm{a}}$

\begin{tabular}{lllll}
\hline Category & Duration & Total THI-hours $>79$ & THI-hours $>84$ & Nighttime recovery (hours $<72$ THI) \\
\hline 1. Slight & Limited: $3-4$ days & $10-25$ & none & Good: $5-10 \mathrm{~h} / \mathrm{night}$ \\
2. Mild & Limited: $3-4$ days & $18-40$ & $<5 /$ day & Some: $3-8 \mathrm{~h} / \mathrm{night}$ \\
3. Moderate & More persistent & $25-50$ & $<6 /$ day & Reduced: $1-6 \mathrm{~h} / \mathrm{night}$ \\
4. Strong & Increased persistence & $33-65$ & $<6 /$ day & Limited: $0-4 \mathrm{~h} / \mathrm{night}$ \\
5. Severe & Very persistent & $40-80$ & $3-15 /$ day over 3 or more days & Very limited: $0-2 \mathrm{~h} / \mathrm{night}$ \\
6. Extreme & Very persistent & $50-100$ & $15-30 /$ days over 3 or more days & Nil: $<1 \mathrm{~h} / \mathrm{night} \mathrm{over} 3$ or more days
\end{tabular}

${ }^{a}$ Environmental factors other than temperature and humidity (e.g., solar radiation, windspeed) and biological factors (e.g., heat tolerance/ sensitivity, diet, acclimation to heat) can modify the potential impact of given environments on feedlot cattle. Severe-to-extreme category conditions can be lethal for vulnerable cattle when combined with high solar radiation levels and low windspeeds, especially when maximum THI is 86 or higher; such conditions were prevalent in the 1995 heat wave which caused more than 4,000 feedlot cattle deaths in the central United States (Hahn and Mader 1997) 
duced as the daily accumulation of hours $\mathrm{x}$ (THI-79), and heat waves were categorized accordingly. An additional factor of night-time cooling was added by totaling the hours that the temperature was below THI 72. Early in the season a mild heat wave would be considered dangerous, while late in the season a strong heat wave could be less dangerous as a result of acclimatization. However, the categories of slight to extreme give producers a gauge to judge the severity of conditions.

Based on that 43-year period, it was apparent that these occasional and localized challenges were important. In addition, WMO reported that the 1990s was the warmest decade on record since widespread measurements began in 1860 , with 4 of the 10 warmest years on record occurring during the 1990s. For projected global warming, application of the response models to GCM scenarios, primarily manifested as increases in air temperature, suggest markedly reduced production levels for swine, beef, and dairy in parts of the United States (Frank et al. 2001). Rational decisionmaking involves knowledge about: (1) the threshold limits beyond which performance penalties (including health and well-being) can be expected for an animal population exposed to potential environmental stressors; (2) the rate at which performance is adversely affected when the thresholds are exceeded; and (3) the likelihood that the animal population of concern will be at risk from either short-term or chronic thermal stressors. In light of these facts, it is imperative that increased attention be focused on animal response and the mitigation of heat stress impacts on livestock.

\section{Animal responses}

Responses of animals vary according to the type of thermal challenge: short-term adaptive changes in behavioral, physiological, and immunological functions (survival-oriented) are the initial responses to acute events, while longer-term challenges impact performance-oriented responses (e.g., altered feed intake and heat loss which affect growth, reproduction, and efficiency). Within limits delineated by thresholds for disrupted behavior and maladapted physiology and immune functions, farm animals can cope with many acute thermal challenges through acclimatization to minimize adverse effects and compensation for reduced performance during moderate environmental challenges. These responses to environmental challenges are illustrated in Fig. 1 (adapted from Hahn and Morrow-Tesch 1993). The interrelationship between potential environmental challenges and the dynamic response of an animal is apparent. Biotechnology will likely alter some of the biological and adaptive responses; however, the laws of physics will still apply - heat production and heat losses must balance within the limits of heat storage capacity of the animals.

In regard to these changing responses, farm animals are remarkable in their adaptive ability to mobilize coping mechanisms when challenged by environmental stressors. However, not all coping capabilities are mobilized at the same time. Cattle require about 3-4 days after the onset of a heat challenge to fully counter the effects of the exogenous
Fig. 1 Response model for farm animals with thermal environmental challenges (Hahn 1999)

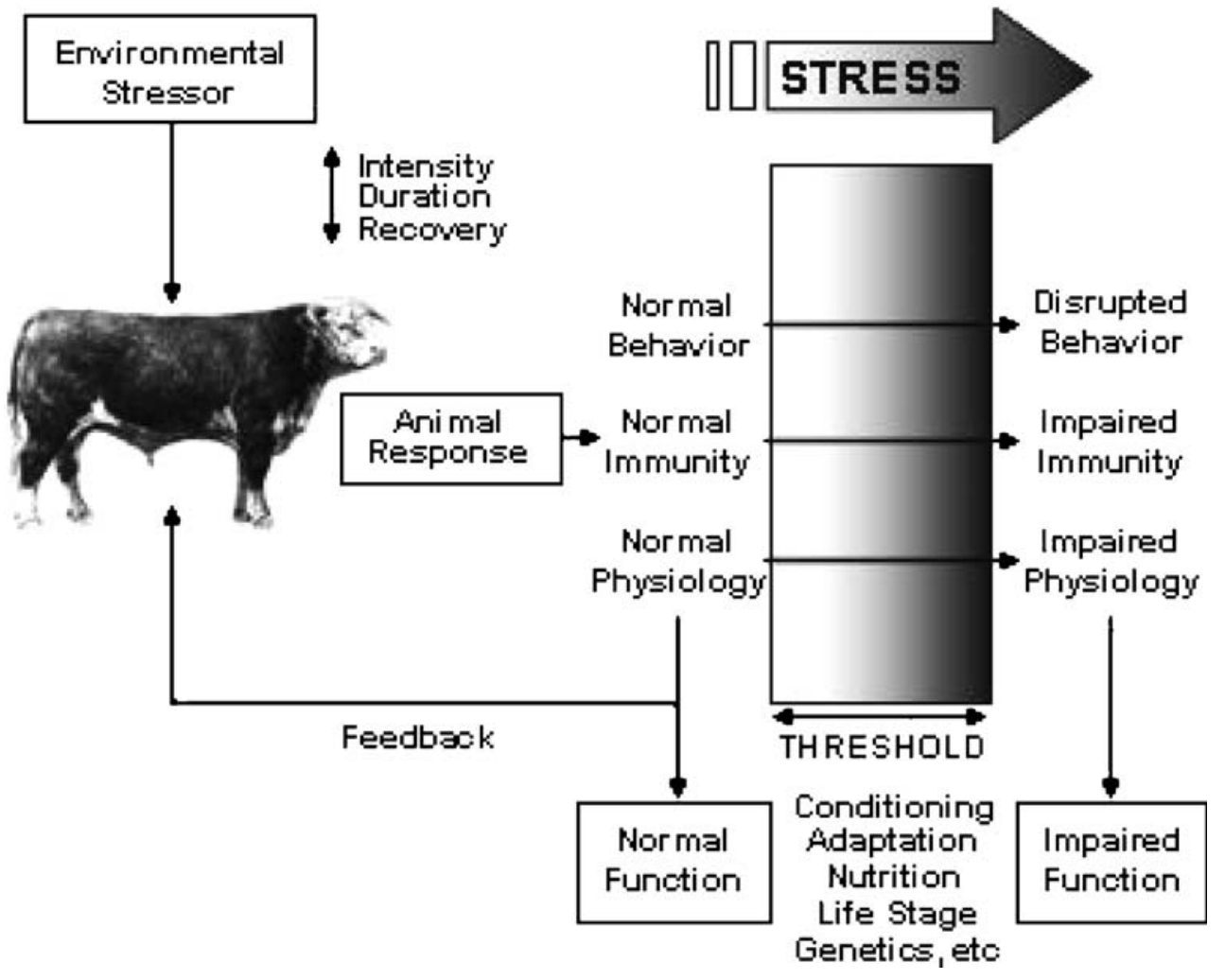


heat load (Hahn 1995a; Hahn and Mader 1997; Hahn 1999; Nienaber et al. 2001). Even though feed intake (FI) reduction usually occurs on the 1st day of hot conditions, the digestive and endogenous metabolic heat load from existing rumen contents adds to the increased exogenous environmental heat load. When considered in terms of a heat wave event, the 3-4 day lag is why cattle deaths often occur on or about the 3rd day of severe conditions (Hahn and Mader 1997). Night-time recovery also has shown to be an essential element of survival when severe heat challenges occur (Scott et al. 1983; Hahn and Mader 1997).

As a general model for mammals of all species, respiration rate (RR) serves as an early warning of increasing thermal stress, and increases markedly above a baseline as the animals try to maintain homeothermy by dissipating excess heat. Above a threshold environmental condition, body temperature (BT) begins to increase as a result of the animal's inability to adequately dissipate the excess heat load by increased respiratory vaporization. There is a concomitant decrease in FI as BT increases, which ultimately results in reduced performance (production, reproduction), health, and well-being if adverse conditions persist (Hahn and Mader 1997; Berman 2005). Thresholds, such as noted in Fig. 1, are species dependent, and are affected by many factors. An example is the recent study (Brown-Brandl et al. 2005) that showed the influence of condition, genotype, respiratory pneumonia, and temperament on RR of unshaded Bos taurus heifers; Fig. 2 illustrates the RR response of different genotypes to environmental temperature.

Monitoring animal performance in measured thermal environments over longer periods of time (weeks to months) permits development of response functions, such as for growth, milk production or other performance measures as functions of air temperature or the THI (Hahn et al. 2003). An animal model to estimate productive performance penalties has been developed, tested, and used in decisions relating to management and housing for milk production of dairy cows in hot environments (Hahn and Osburn 1969). A quantitative relationship between milk production decline

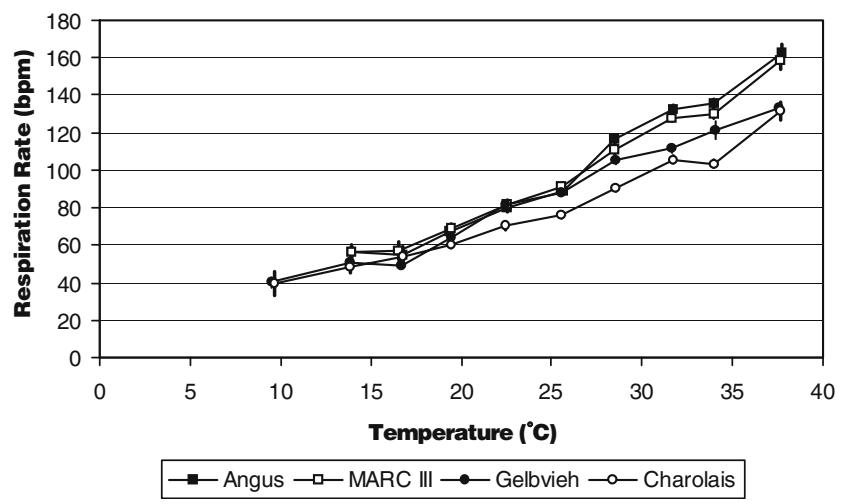

Fig. 2 Respiration rate (RR) as a function of ambient temperature for unshaded cattle of four genotypes (Brown-Brandl et al. 2005)

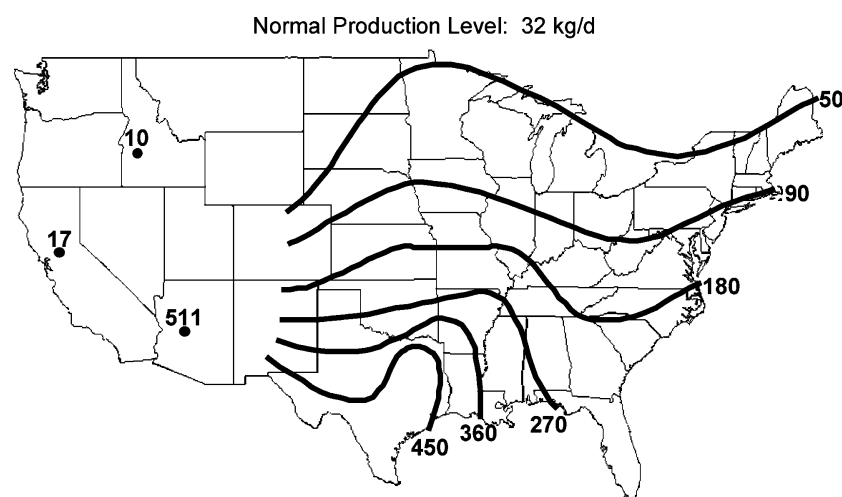

Fig. 3 Expected milk declines ( $\mathrm{kg} / \mathrm{cow})$ during the 122-day summer period 1 June through 30 September for dairy cows normally producing $32 \mathrm{~kg} /$ day (Hahn and Osburn 1969)

and the THI, with normal milk production level included as a parameter, served as the basis for establishment of a probabilistic approach for determining expected milk production decline. Milk production declines predicted by this method have been verified as reasonable. Expected summer milk production declines have been estimated for several locations in the United States (Fig. 3). In the development of such response functions, however, compensatory capabilities of the animals may affect the threshold for performance losses, as they have considerable ability to rebound after stressors are removed (Hahn 1982). Compensatory capabilities seem to exist for a relatively broad range of factors when performance penalties are slight to moderate. Obviously, there are linkages between the dynamic, short-term responses which influence FI and compensatory capabilities, and the longer-term performance responses that depend on FI, with the longer-term serving as the basis for strategic decisions about potential mitigation measures.

Management of livestock is discussed in the next section, but some type of response indicator is needed to optimize management (Gaughan et al. 2000). An automatic weather station located on-site will provide valuable meteorological data for feedlots (Meat \& Livestock Australia 2002). A recent experiment reported RRs of beef cattle penned individually during daylight hours over the summer months to establish thresholds related to management of feedlot animals (Eigenberg et al. 2005). Variables of temperature $\left(t_{\mathrm{db}}\right)$, dew-point $\left(t_{\mathrm{dp}}\right)$, wind speed $\left(v_{\mathrm{w}}\right)$, and solar radiation $\left(r_{\mathrm{s}}\right)$ were measured and a functional relationship was developed for observed RR when drybulb temperature exceeded $25^{\circ} \mathrm{C}$.

$$
\begin{aligned}
R R & =2.8 t_{d b}+2.4 t_{d p}-1.5 v_{w}+0.038 r_{s}-52.8 \\
R^{2} & =0.45
\end{aligned}
$$

On the basis of Eq. 2, equivalent THI thresholds shown in Table 2 were developed for RRs, assuming a solar radiation 
Table 2 Temperature-humidity index (THI) thresholds related to respiration rate $(\mathrm{RR})$ from Eq. 2

\begin{tabular}{lll}
\hline Threshold & THI & RR, breaths $\mathrm{min}^{-1}$ \\
\hline Normal & $<74.0$ & $<90$ \\
Alert & $>74-<79$ & $90-110$ \\
Danger & $>79-<84$ & $110-130$ \\
Emergency & $>84$ & $>130$ \\
\hline
\end{tabular}

of $800 \mathrm{Wm}^{-2}$, a wind speed of $0 \mathrm{~ms}^{-1}$, dry-bulb temperature range of 25 to $40^{\circ} \mathrm{C}$, and $\mathrm{RH}$ between 30 and $50 \%$.

Berman (2005) determined environmental threshold temperatures for dairy cows based on environmental factors and characteristics of the cows. Environmental factors included temperature, humidity, wind speed, and direction, while cow characteristics included body weight, milk production level, and hair coat depth. The threshold temperatures signaled when environmental intervention should begin in order to limit production loss.

Quantification of these potential impacts of climate on livestock production allows producers to gain a better understanding of the magnitude of the changes in production levels and potential indicators of livestock response, on which to base management actions. Projected economic losses resulting from temperature-induced reductions in production may justify mitigation of these temperature increases through changes in management practices, such as installation of sprinklers in feedlots, evaporative cooling of barns, feeding and nutritional strategies, and/or selection of more heat-tolerant animals.

\section{Management practices}

Proactive environmental management can reduce or eliminate potential losses resulting from thermal challenges (Hahn 1985; Meat \& Livestock Australia 2002). Hahn (1995a) considered risk for livestock production systems in the context of heat challenges in terms of three elements: perception, assessment, and management. Based on Simensen (1984), the concept of risk associated with threshold limits for performance losses and increased levels of vulnerability as influenced by animal and environmental parameters can be described as follows: (1) when genetic, performance level and environmental influences combine to create a low level of vulnerability, there is little risk of performance losses or death; (2) an increased performance level, such as in a moderately high-producing dairy cow, or a fast-growing beef animal near market weight, increases the vulnerability of the animal; coupling that with an adverse environmental situation can put the animal at risk; (3) a high-performance animal, even in a moderate environment, can be at increased risk; (4) combining an adverse environment with high performance animals pushes the level of vulnerability and consequent risk of reduced performance (and potential death) to even higher levels. Inherent genetic characteristics, which are disadvantageous to the animal in adapting to or coping with the environment, also puts the animal at increased risk; that situation, when combined with a high performance level, means that any environment other than near-optimal can increase animal vulnerability and risk of major consequences to unacceptable levels. Vulnerable cattle can be identified and managed to reduce their risk of excessive heat load (Meat \& Livestock Australia 2002). The heat wave category information presented in Table 1 has strategic value to the feedlot manager in deciding on selecting and providing shades, sprinklers, or other environmental modification equipment that will provide emergency measures to ensure survival of the animals, as well as mitigation measures for reducing adverse consequences.

Several management practices are available to ameliorate heat stress, each with positive and negative properties. Housing provides the most potential control over environmental parameters; however, it comes at a relatively high initial investment cost per head. It may also lead to other production constraints, and certainly requires intensive management of livestock wastes whether flushed from the structure, accumulated within a manure pit beneath the livestock, or in the form of bedding material. Housing is common for some production systems such as swine, poultry, and dairy systems where both environmental modification and animal management are important benefits. However, for species such as cattle, the high respiration and manure moisture loads require extensive ventilation under both hot and cold climates, with the probable addition of make-up heat for cold climates. For cattle, the opposing cost factor of increased cost with increased space is counter to the reduced performance that can result from reduced space.

Ventilation systems within livestock housing are critical to operations and greatly impact the initial investment, energy consumption, and cooling capacity. For warm or hot conditions, increased airflow rate, spray cooling, and evaporative cooling can be added to ventilation systems with increased cooling effectiveness, but also increased costs. In general, spray cooling and evaporative cooling are dependent on the moisture holding capacity of ventilation air, but even humid environments can benefit (Table 3 in Hahn and Osburn 1969). Khongdee et al. (2006) have shown specific benefits for dairy cows in hot humid conditions. Tunnel ventilation systems, characterized by a bank of fans on one end of the building with inlets on the opposite end, are designed to achieve a specific air speed to optimize convective heat loss (Gooch and Stowell 2003; Bray et al. 2003). Addition of spray cooling, such as a mist injected in the airstream to provide evaporative cooling of the air, increases humidity but reduces air temperatures. To 
achieve greater heat losses from animal surfaces, droplets (not mist) of water must wet the hide, as it is the drying process from the animal's hide that removes heat from the animal. A mist applied on the animal could accumulate on the hair without wetting the hide and actually reduce effective heat loss. However, for dairy cows, health problems (e.g., mastitis) may result if the resting area is wetted.

For those livestock species requiring less protection from climatic stressors, shade is a valuable technique as it blocks $30 \%$ of solar radiation (Bond et al. 1961) and substantially reduces heat load under heat stress conditions. Shades can improve animal comfort and productivity, and should be designed to maximize ventilation and protection from the afternoon solar load (Meat \& Livestock Australia 2002). Kelly and Bond (1958) completed extensive comparisons of shade materials. Hahn et al. (1962) and Bond et al. (1967) determined the impact of roof size and orientation on the effectiveness of shade structures. Figure 4 (Garrett 1963) shows a projected area of the continental United States that should benefit from shade. The projection is based on the accumulative hours of the year when the temperature is above $29.4^{\circ} \mathrm{C}$.

Natural ventilation generally refers to structures achieving airflow without fans; however, outdoor airflow is just as critical. During cold weather, chill factors represent the combined effects of air temperature and air speed to represent greater convective heat loss from animals. However, in hot weather, greater convective heat loss can be a matter of survival (Mader et al. 1999). Therefore, it is imperative that local features such as windbreaks, and even topography, be considered in pen design. A cornfield planted adjacent to a feedlot can block substantially more air flow than a short crop, such as alfalfa, when in the direction of the prevailing winds. The same can be said of locating pens on the leeward side of even a gentle slope. Mounds within a feedlot will be used by cattle to maximize exposure to airflow and demonstrate the importance of local features (microclimate) within pens.

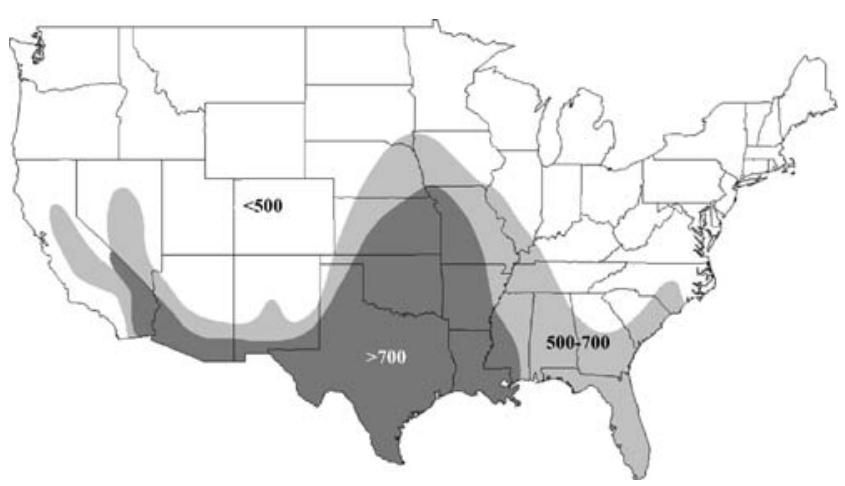

Fig. 4 Areas of the mainland United States having selected categories of yearly hours above $29.4^{\circ} \mathrm{C}$ (Garrett 1963)
High pressure irrigation-type sprinklers can provide inexpensive wetting of animals in open pens, and effectiveness is enhanced when coupled with fans. However, to be most effective, the system should be predesigned and operational before heat stress is encountered. Guidelines established by Morrison et al. $(1972,1981)$ provide valuable design criteria. Reports by Turner et al. (1992), Brouk et al. (2003), Calegari et al. (2003), and Collier et al. (2006) have also documented the beneficial use of water spray, with or without fans, on dairy cows to enhance production during periods of heat stress.

Portable tank wagons with high-pressure sprayers have been used to provide animal wetting, but efficiency and effectiveness are limited. In a crisis situation, local fire departments have been called to spray water on cattle as a last resort, but the method is not always effective or timely. Davis and Mader (2001) found that periodically wetting the feedlot surface without wetting animals reduced feedlot surface temperature and provided some heat stress relief.

Wallows have long been used to provide heat stress relief for swine, to wet the skin and provide a heat sink. However, cattle will also be drawn to ponded water or streams if available, to wet their skin and accelerate heat loss, espepcially through increased blood flow to the legs. However, sanitation becomes an issue within the wallows, ponds, or streams and many local environmental regulations ban the use of stream access to production livestock.

Heat stress generally causes cattle to crowd or bunch, probably to control flies, but possibly to take advantage of the limited shade cast by the other bodies or preference for other body surface temperatures compared to higher surrounding surface temperatures. Many of the behavioral adjustments of livestock can be counter-productive, as the crowding also blocks airflow and reduces both convective and evaporative heat loss. However, in some management systems, area is reduced within a feedlot to increase moisture content of the surface of the pen, and reduce dust generation as animals mill around the pen. Dust generation can add to the complications of heat stress in the form of increased respiratory problems for the livestock.

Milling of cattle at dusk creates large clouds of feedlot dust, generally at a time of minimal wind speed. Mitlöhner (2000) suggested that the milling activity was stereotypical of feeding at dusk and could be reduced or eliminated by feeding at that time of the day. This management practice utilizes some of the behavioral characteristics to enhance productivity and reduce dust clouds. In addition, eating at dusk distributes the resulting metabolic heat load and lessens one heat stress factor. Highly digestible high-energy rations are an effective form of summer diet that help animals control body temperature by reduction of excess heat (Meat \& Livestock Australia 2002). Other feed management practices have been tested (Mader et al. 
2002; Nienaber et al. 2001) with mixed results. Generally, if feed restriction of cattle is imposed, there is a reduction in growth with only limited reduction in body temperature and heat stress. Finally, it is essential that all animals have access to an adequate supply of cool, good quality water (Meat \& Livestock Australia 2002; MWPS 1987).

Handling of animals during peak body temperature hours (mid-day to late afternoon) should be avoided during potential heat stress periods. Any forced animal activity will generate increased body temperature and additional heat stress. Weighing, shipping, or routine treatment of animals should be scheduled for evening or early morning hours, or even during the night to provide an opportunity for animals to cool down after the increased activity.

Animals medicated for respiratory illnesses were under substantially higher risk of heat stress than non-treated animals (Brown-Brandl et al. 2005). Dark-hided cattle were at much greater risk of heat stress than light-colored cattle as measured by RR. This substantiates the findings of Hungerford et al. (2000) and Mader et al. (2001), who reported greater risks of dark-hided cattle based on heat wave fatalities in the feedlot. A risk assessment model to describe the animal characteristics contributing to heat stress risk has been developed to assist producers in early identification of livestock that are at a higher risk of heat stress reactions (Brown-Brandl et al. 2006). Increased observation of those animals and special care (e g., shade or cooling) can be beneficial.
A Livestock Safety Monitor (LSM) has been developed by Eigenberg et al. (2006), to provide an early warning device for producers based on "real time" weather conditions. The LSM uses current weather parameters of temperature, humidity, air speed, and solar radiation to determine heat stress as characterized by RR. The LSM uses the categories presented in Table 2 to provide producers with on-site projections of animals' responses to the current conditions as another tool to help producers be aware of dangerous conditions. Gaughan et al. (2005) has used a similar approach on a regional basis in Australia by providing warnings of dangerous weather conditions, based on weather forecasts.

These management practices and rational selection of those methods most applicable to individual operations were summarized by Hahn (1981) as a decision tree shown in Fig. 5. Risk management takes place when decisions must be made to either do nothing, or do something to mitigate losses, after perceived risks have been assessed. If the decision is to do something, then strategies must be developed (e.g., providing shades and/or sprinklers) for tactical use when the need arises to cope with a weather event (e.g., a heat wave). There are two approaches: "crisis management," whereby managers react after a challenging thermal situation develops (and accept the consequences), or "proactive risk management," whereby livestock managers recognize the threat of thermal challenges, assess the potential consequences, make strategic plans for mitigation, and prepare to take tactical action(s) to avert or reduce the threat.
Fig. 5 Decision tree for evaluation of environmental management options adapted from Hahn (1981)

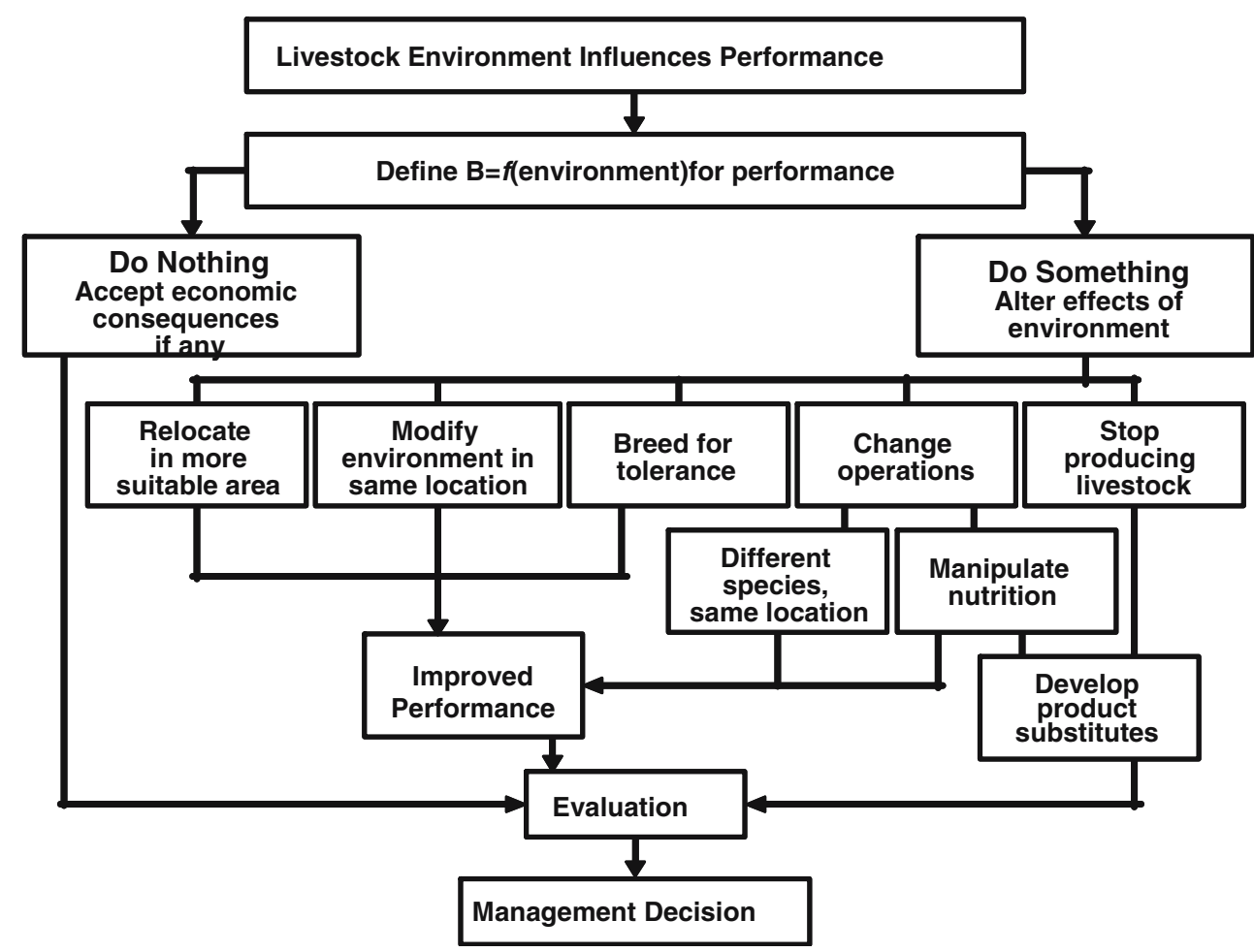




\section{Conclusions and a look ahead}

The adaptive capabilities of animals and livestock production systems have been emphasized in this report. Biometeorology has a key role in rational management to meet the challenges of thermal environments for livestock production systems, whether in current or altered climates. While the focus is primarily on cattle in warm or hot climates, the importance of dynamic animal responses to environmental challenges applies to all species and climates. Risk management, by considering perceived thermal challenges, then assessing the potential consequences and acting accordingly, will reduce the impact of such challenges. Summarizing, the most important element of proactive environmental management to reduce risk is preparation: (1) be informed; (2) develop a strategic plan; (3) observe and recognize animals in distress; (4) take appropriate tactical action.

Precision agriculture will undoubtedly become more prevalent in livestock production system management. A recent Japanese-Danish Workshop on IT Utilization of Improved Functional Environment ${ }^{1}$ in Animal Industry (Takai and Ikeguchi 2000) highlights several such potential applications. In this context, future management will be increasingly based on biological information. The concept of "management by exception," introduced by Hyde et al. (1981), was an early attempt to implement precision agriculture with respect to identification of low-producing dairy cows on the basis of feeding behavior. The risk assessment model under development by Brown-Brandl et al. (2006) focuses on individual animals that would benefit from special care (e.g., shade, cooling). Sensors to monitor individual animal physiological responses [e.g., RR (Eigenberg et al. 2000); body temperature (Hahn et al. 1990)] and lowcost video cameras to monitor activities already exist. Linking such sensors and cameras to a computer network provides for monitoring and control purposes through Decision Support Systems ${ }^{2}$ (DSS). The DSS provides for evaluating various (often conflicting) factors in management decisions, so that the concept of functional environments becomes operational, potentially at the individual animal level, to promote optimal treatment for performance, health, and well-being in the face of thermal challenges, whether from current or altered climates.

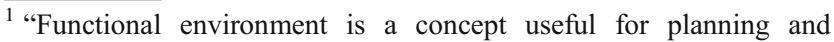
creating animal production systems that altogether comply with the given demands in the best possible way for the benefit of the overall production demands." (Takai and Ikeguchi 2000).

2 There is much still to be done to develop biologic response functions needed to transform biological knowledge/data into useful information applicable for rational decision-making.
}

\section{References}

ASAE (2003) Design of ventilation systems for poultry and livestock shelters. ASAE Standard EP270.5 FEB03. ASAE, St Joseph, MI

ASHRAE (2005) Fundamentals SI. Environmental control for animals and plants-physiological considerations. ASHRAE, Atlanta, GA

Berman A (2005) Estimates of heat stress relief needs for Holstein dairy cows. J Anim Sci 83:1377-1384

Blackshaw JK, Blackshaw AW (1991) Effects of shade on production and welfare of feedlot beef cattle: roles of animal and environmental factors in heat stress. Report of the Dept. of Farm Animal Medicine and Production, and the Department of Physiology and Pharmacology, University of Queensland. St. Lucia, Australia

Bond TE, Kelly CF, Garrett WN, Hahn GL (1961) Evaluation of materials for livestock shades. California Agric 15:7-8

Bond TE, Kelly CF, Morrison SR, Pereira N (1967) Solar, atmospheric, and terrestrial radiation received by shaded and unshaded animals. Trans ASAE 10:622-629

Bray DR, Bucklin RA, Carlos L, Cavalho V (2003) Environmental temperatures in a tunnel ventilated barn and in an air conditioned barn in Florida. In: Proceedings, Fifth International Dairy Housing Conference, 29-31 January 2003, Fort Worth, Texas. ASAE, St Joseph, MI

Brouk MJ, Smith JF, Harner JP III (2003) Effect of sprinkling frequency and airflow on respiration rate, body surface temperature and body temperature of heat stressed dairy cattle. In: Proceedings, Fifth International Dairy Housing Conference, 2931 January 2003, Fort Worth, Texas. ASAE, St Joseph, MI

Brown-Brandl T, Eigenberg RA, Nienaber JA (2005) Heat stress risk factors for feedlot heifers. In: Proceedings, Seventh International Livestock Environment Symposium, 18-20 May 2005, Beijing, China. ASAE, St Joseph, MI

Brown-Brandl TM, Nienaber JA, Eigenberg RA, Mader TL, Morrow JL, Dailey JW (2006) Comparison of heat tolerance of feedlot heifers of different breeds. Livestock Sci 105:19-26

Calegari F, Calamari L, Frazzi E (2003) Effects of ventilation and misting on behaviour of dairy cattle in the hot season in south Italy. In: Proceedings, Fifth International Dairy Housing Conference, 29-31 January 2003, Fort Worth, Texas.ASAE, St Joseph, MI

Collier RJ, Dahl GE, VanBaale MJ (2006) Major advances associated with environmental effects on dairy cattle. J Dairy Sci 89:1244-1253

Davis MS, Mader TL (2001) Effects of water application to feedlot surface during the summer. In: Proceedings, Sixth International Livestock Environment Symposium, 21-23 May 2001. Louisville, Kentucky. ASAE, St Joseph, MI

Eigenberg RA, Hahn GL, Nienaber JA, Brown-Brandl T, Spiers D (2000) Development of a new RR monitor for cattle. Trans ASAE 43:723-728

Eigenberg RA, Brown-Brandl TM, Nienaber JA, Hahn GL (2005) Dynamic response indicators of heat stress in shaded and nonshaded feedlot cattle. Part 2: Predictive relationships. Biosystems Eng 9:111-118

Eigenberg RA, Brown-Brandl TM, Nienaber JA (2006) Development of a livestock weather safety monitor for feedlot cattle. Appl Eng Agric (in press)

Flaba J, Bickert W, Capdeville J, Georg H, Kaufmann R, Len JJ, Loynes J, Poellinger A, Tillie M, Ventorp M, Zappavigna P (2002) The design of beef cattle housing, report of the CIGR section II working group $\mathrm{n}^{\circ} 14$ cattle housing. Paper No. 024026. ASAE, St Joseph, MI

Frank KL, Mader TL, Harrington JA Jr., Hahn GL, Davis MS (2001) Climate change effects on livestock production in the Great Plains. In: Proceedings, Sixth International Livestock Environment Symposium, 21-23 May 2001, Louisville, Kentucky. ASAE, St Joseph, MI 
Garrett WN (1963) Importance of environment and facilities in beef production. Unpublished manuscript prepared for Symposium presentation at American Society Animal Science Meeting, Corvallis, Oregon

Gaughan JB, Holt SM, Hahn GL, Mader TL, Eigenberg R (2000) Respiration rate-is it a good measure of heat stress in cattle? Asian-Australas J Anim Sci 77 [Suppl C]:329-332

Gaughan JB, Byrne T, Lott S, Binns P, Killip C (2005) Reducing the risk of heat load for the Australian feedlot industry. Final Report Project Number FLOT.327. Meat \& Livestock Australia, Sydney NSW

Gooch CA, Stowell RR (2003) Tunnel ventilation for freestall facilities - design, environmental conditions, cow behavior, and economics. In: Proceedings, Fifth International Dairy Housing Conference, 29-31 January 2003, Fort Worth, Texas. ASAE, St Joseph, MI

Hahn GL (1981) Housing and management to reduce climatic impacts on livestock. J Anim Sci 52:175-186

Hahn GL (1982) Compensatory performances in livestock: influences on environmental criteria. In: Proceedings, Second International Livestock Environment Symposium, 20-23 April 1982, Ames, Iowa. ASAE, St Joseph, MI

Hahn GL (1985) Management and housing of farm animals in hot environments. In: Yousef M (ed) Stress physiology in livestock. CRC, Boca Raton, pp 151-174

Hahn GL (1995a) Global warming and potential impacts on cattle and swine in tropical and temperate areas. In: Proceedings, First Brazilian Congress on Biometeorology, 4-6 September 1995 Jaboticabal, SP, Brazil

Hahn GL (1995b) Environmental management for improved livestock performance, health and well-being. Jpn J Livestock Manage 30:113-127

Hahn GL (1999) Dynamic responses of cattle to thermal heat loads. J Anim Sci 77[Suppl 2]:10-20

Hahn GL, Mader TL (1997) Heat waves in relation to thermoregulation, feeding behavior and mortality of feedlot cattle. In: Proceedings, Fifth International Livestock Environment Symposium, May 1997. Bloomington, Minnesota. ASAE, St Joseph, MI

Hahn GL, Morrow-Tesch JL (1993) Improving livestock care and well-being. Agric Eng 74:14-17

Hahn GL, Osburn DD (1969) Feasibility of summer environmental control for dairy cattle based on expected production losses. Trans ASAE 12:448-451

Hahn GL, Kelly CF, McKillop AA, Bond TE (1962) The relation of roof size to temperatures of irradiated metal roof sections exposed to forced convection. Ag Research Service Bulletin Series ARS 42-58

Hahn GL, Eigenberg RA, Nienaber JA, Littledike ET (1990) Measuring physiological responses of animals to stressors using a microcomputer-based portable datalogger. J Anim Sci 68:2658-2665

Hahn GL, Mader TL, Gaughan JB, Hu Q, Nienaber JA (1999) Heat waves and their impacts on feedlot cattle. In: Proceedings, 15th International Society Biometeorology Congress, 353-357 (ICB Paper No. 11.1), September 1999. Sydney, Australia

Hahn GL, Mader TL, Eigenberg RA (2003) Perspective on development of thermal indices for animal studies and management. In: Lacetera N, Bernabucci U, Khalifa H, Ronchi B, Nardone A (eds) Interactions Between Climate and Animal Production EAAP Tech Series No. 7, Wageningen, The Netherlands (ISBN 9076998264)
Hungerford LL, Buhman MJ, Dewell RD, Mader TL, Griffin D, Smith DR, Nienaber JA (2000) Investigation of heat stress mortality in four midwest feedlots. In: Proceedings, International Symposium on Vet Epid and Econ, August 2000. Breckenridge, CO, \#616

Hyde GM, Puckett HB, Olver EF, Harshbarger KE (1981) A step toward dairy heard management by exception. Trans ASAE 24:202-207

Kelly CF, Bond TE (1958) Effectiveness of artificial shade material. Agric Engn 39:758

Khongdee S, Chaiyabutr N, Hinch G, Markvichitr K, Vajrakubkka C (2006) Effects of evaporative cooling on reproduction performance and milk production of dairy cows in hot wet conditions. Int J Biometeorol 50:253-257

LCI (1970) Patterns of transit losses. Livestock Conservation, Omaha, NE

Mader TL, Dahlquist JM, Hahn GL, Gaughan JB (1999) Shade and wind barrier effects on summer-time feedlot cattle performance. J Anim Sci 77:2065-2072

Mader TL, Holt SM, Gaughan JB, Hahn GL, Davis MS, Parkhurst AM, Spiers DE (2001) Heat load management for feedlot cattle. In: Proceedings, Sixth International Livestock Environment Symposium. Louisville, Kentucky 2001. ASAE, St Joseph, MI, 147-153

Mader TL, Holt SM, Hahn GL, Davis MS, Spiers DE (2002) Feeding strategies for managing heat load in feedlot cattle. J Anim Sci 80:2373-2382

Meat \& Livestock Australia (2002) Heat load in feedlot cattle 2002. Meat \& Livestock Australia Limited, Feedlot: FL08-FL13

Mitlöhner FM (2000) Behavioral and environmental management of feedlot cattle (Dissertation). Texas Tech University, Lubbock, Texas

Morrison SR, Given RC, Lofgreen GP (1972) Sprinkling cattle for relief from heat stress. J Anim Sci 36:428-433

Morrison SR, Prokap M, Lofgreen GP (1981) Sprinkling cattle for heat stress relief: activation temperature, duration of sprinkling and pen area sprinkled. Trans ASAE 24:1299-1305

MWPS (1987) Beef Housing and Equipment Handbook. Publication MWPS-6, 4th edn, Midwest Plan Service, Ames, Iowa

Nienaber JA, Hahn GL, Eigenberg RA, Brown-Brandl TM, Gaughan JB (2001) Feed intake response of heat-challenged cattle. In: Proceedings, Sixth International Livestock Environment Symposium. Louisville, Kentucky 2001.ASAE, St Joseph, MI, 154-164

Oliver JC, Hellman MH, Bishop SE, Pelissier CL, Bennett LF (1979) Heat stress survey. Calif Agric 33:6-8

Scott IM, Johnson HD, Hahn GL (1983) Effect of programmed diurnal temperature cycles on plasma thyroxine level, body temperature, and feed intake of Holstein dairy cows. Int J Biometeorol 27:47-62

Simensen E (1984) Livestock environment and health-general concepts and research strategies. Report 7, Dept Animal Husbandry and Genetics. Norwegian College of Veterinary Medicine, Oslo

Takai H, Ikeguchi A (2000) Summary of Japan-Denmark Workshop on IT Utilization of Improved Functional Environment in Animal Industry. Tsukuba, Japan (ISBN 4-921201-45-5)

Thom EC (1959) The discomfort index. Weatherwise 12:57-59

Turner LW, Chastain JP, Hemken RW, Gates RS, Crist WL (1992) Reducing heat stress in dairy cows through sprinkler and fan cooling. Appl Eng Agric 8:251-256

USAgNet.com (2006) California's Cattle Death Toll Surpasses 25,000 [Online] Available URL: http://www.wisconsinagconnection. com/story-national.cfm?ID $=1479 \& \mathrm{yr}=2006$ 